\title{
Lay Beliefs about the Causes and Treatments of Schizophrenia
}

Subin Park ${ }^{1}$, Minji Lee ${ }^{1}$, Adrian Furnham², Mina Jeon ${ }^{3}$, Young-Mi Ko ${ }^{1}$

${ }^{1}$ Department of Research Planning, Mental Health Research Institute, National Center for Mental Health, Seoul, Korea

${ }^{2}$ Research Department of Clinical, Educational and Health Psychology, University College London, United Kingdom

${ }^{3}$ Department of Psychology and Human Development, University College London, United Kingdom 


\begin{abstract}
Background: Lay beliefs about schizophrenia are an important factor associated with treatment-seeking behavior. Aims: This study was conducted to investigate the lay beliefs about the causes and treatments of schizophrenia in South Korea.

Methods: A total of 654 adults (mean age $35.96 \pm 11.33$ years) completed two questionnaires assessing their views on the causes and cures of schizophrenia. The factor structures of lay beliefs about the causes and treatments of schizophrenia were then analyzed and the correlations between the resultant factors investigated.

Results: From the cause items, four factors were extracted: Health/Lifestyle, God/Fate, Social/Environmental, and Biological. Four factors were also extracted from the treatment items: Self-help/Stress Management, Physical Treatment/Health Management, Religious Help, and Mental Health Service Utilization. Notably, most participants believed that items in the Social/Environmental and Biological factors were the causes of schizophrenia, while they believed that items in the Mental Health Service Utilization and 'Self-help/Stress Management factors were the treatments. Participants' beliefs about the causes and treatments of schizophrenia were systematically correlated.

Conclusion: Overall, laypeople have reasonably accurate beliefs and a multidimensional view of the causes and treatments of schizophrenia. Nevertheless, our results suggest that public education about the etiology and treatment of schizophrenia are necessary to increase actual usage of mental health services and treatments for schizophrenia.
\end{abstract}

Keywords: Beliefs, causes, South Korea, schizophrenia, treatments 


\section{Introduction}

The World Health Organization(WHO)(2016) has reported that about 21 million people worldwide suffer from schizophrenia. The overall prevalence of schizophrenia has been shown to vary across countries from $0.3 \%$ to 0.7\%(Association, 2013). In South Korea, the prevalence of schizophrenia was $0.1 \%$ (Cho et al., 2010). However, even though schizophrenia is evidently not a rare problem, the difference between the overall prevalence of schizophrenia and the proportion of individuals with the disorder who actually obtain treatment is considerable, with the estimated median treatment gap worldwide being $32.2 \%$ (range 5.9\% to $61.5 \%$ ) (Kohn, Saxena, Levav, \& Saraceno, 2004).

Research on mental health service usage has shown that ignorance, lack of knowledge, incorrect beliefs, stigma, and perceived discrimination of mental health status and the treatment of it are the main reasons that people do not seek out or utilize mental health services (Corrigan, Druss, \& Perlick, 2014; Thornicroft, 2008; Vogt, 2011).Particularly, having inaccurate information about mental health might lead individuals to misunderstand mental illness which could produce prejudice and discrimination toward mental illness or hinder the help-seeking behavior of those affected which may ultimately lead to more serious consequences such as delaying of appropriate intervention, increased burden on the mental health care system, and aggravation of symptoms that could have been treated with earlier interventions (Jorm, 2000; Lauber, Nordt, Falcato, \& Rössler, 2003). Schizophrenia is a major disorder that can have serious consequences for delayed treatment and can cause considerable personal and socialburden(Chang et al., 2008; Knapp, Mangalore, \& Simon, 2004),although early treatmentcan have a critical impact on the onset and recovery rate(Judge, Perkins, Nieri, \& Penn, 2005). Therefore, it is exceedingly important to understand laypeople's level of information and beliefs about schizophrenia, as these factors could have a great influence on whether individuals with the disorder seek out appropriate intervention. It would further aid in improving these lay beliefs.

One's knowledge and beliefs about mental disorders are collectively referred to as mental health literacy(MHL)(Jorm, 2000). A number of studies have been conducted on the MHL of schizophrenia(Altweck, Marshall, Ferenczi, \& Lefringhausen, 2015; Angermeyer \& Matschinger, 2003; Angermeyer, Millier, Rémuzat, Refaï, \& Toumi, 2013; A. Furnham \& Igboaka, 2007; Jensen et al., 2016; Lauber et al., 2003; Lee \& Suh, 2010; Magliano et al., 2001; Reavley \& Jorm, 2014; Suh, Kim, \& Byoun, 1995; Yoshioka, Reavley, Rossetto, \& Nakane, 2016), and the results of which appear to differ according to the study population. For instance, studies have shown that relatives of patients with schizophrenia are more likely to believe that psychosocial factors are the main cause of schizophrenia than are biological or genetic factors(Magliano et al., 2001; Suh et al., 
1995).Furthermore, a study on Korean laypeople revealed that they tend to endorse individual psychological causes such as internal conflict and a lack of will rather than socio-environmental, biological, or supernatural causes of schizophrenia (Lee \& Suh, 2010). By contrast, Western studies have shown that laypeople tend to believe that schizophrenia is caused by socio-environmental factors such as negative life events (Angermeyer \& Matschinger, 2003; Angermeyer et al., 2013).

In contrast to these lay beliefs, empirical research has determined that the major causes are abnormal brain structure and circuits, altered neurotransmitter systems, and various genetic and environmental risk factors. Furthermore, the best available treatments appear to be antipsychotic medications (which is the first-line treatment) along with psychological and psychosocial treatments(U Khan, Martin-Montañez, \& Chris Muly, 2013). Notably, a recent study conducted in Denmark showed that the general population has beliefs about the causes of schizophrenia that are in line with professional knowledge: namely, a hereditary explanation followed by improper upbringing and stressful life events(Jensen et al., 2016). However, most studies conducted in South Korea show that people tend to believe in individual psychological causes followed by social environmental causes and show a preference toward psychological counseling and therapy (Lee \& Suh, 2010; Suh et al., 1995).

Lay beliefs on the causes of diseases change over time. For instance, a comparative study within Australia over 16 years showed that the general population shifted from believing schizophrenia to be caused by personality factors such as a weakness of character to believing that it is caused by a combination of childhood adversities and biology (i.e., inherited genetic traits)(Reavley \& Jorm, 2014). Therefore,it is necessary to investigate current beliefs of laypeople regarding the causes of schizophrenia in South Korea to facilitate comparison with the MHL of professionals and worldwide trends.

Thus, the main purpose of this study is to systematically investigate the beliefs of lay people regarding the causes and treatments for schizophrenia in South Korea. Using these data, we can directly promote the use of professional treatment and intervention in the early stage of schizophrenia, and conduct further research on how to improve awareness of schizophrenia and the utilization rate of professional mental health services. The hypotheses of this study, based on the findings of previous studies, are as follows.

H1. Korean laypeople will attribute schizophrenia to psychosocial and biological causes.

H2. The favored treatment of schizophrenia will be psychologicaland psychiatric approaches.

H3. Factor analyses will produce coherent and interpretable categories of the causes and treatments, and the extracted factorswill not contain contradictory items. 
H4. Lay beliefs about causes and treatment of schizophrenia will be internally coherent and therefore strongly correlated.

\section{Methods}

\section{Participants and procedure}

We conducted an online survey on males and females aged15-54 years who were residing in South Korea. This cross-sectional study was conducted from October to November 2016. The survey was distributed by an online survey service provider, which operates a consumer panel website with more than 460,000 potential respondents. The service provider sent an e-mail to a random sample of potential respondents who were registered with their service and had participated in a survey at least once in the past 12 months. Of the 9,631 potential respondents who received an e-mail invitation, 654 (340 males and 314 females; mean age $35.96 \pm 11.33$ years) accessed the service provider's website with their own computers and answered the questionnaire. The questionnaire did not include any questions that would enable us to personally identify them. This research was reviewed and approved by the Institutional Review Board of the National Center for Mental Health (No. 116271-2016-44).

Participants were initially given a description of schizophrenia based on the criteria of the Diagnostic and Statistical Manual of Mental Disorders(DSM-5). More specifically, they were told that schizophrenia is a mental illness with various cognitive, behavioral, and emotional symptoms, such as delusions, hallucinations, disorganized speech, and emotional insensitivity. Next, participants were asked to complete a questionnaire adapted from that created by Farnham and his colleagues to study beliefs about the causes and treatments of mental illness (A. Furnham \& Anthony, 2010; A. Furnham \& Igboaka, 2007; A. Furnham, Ritchie, \& Lay, 2016). It was altered appropriately to better fit Korea's situation. Specifically, they had to rate whether they agreed with each of 34 and 33 statements about the causes and treatments of schizophrenia, respectively. They rated their agreement on a scale of 1 (completely disagree) to 7 (completely agree).

\section{Statistical analyses}

Descriptive statistics (mean \pm standard deviation) were calculated to describe the basic features of the data. Then, an exploratory factor analysis using the varimax rotation was performed separately for the causes and treatment sections of the questionnaire. Pearson correlation analysis was performed to analyze the correlations between the scores of the cause and treatment factors. SPSS Statistics 21.0 (IBM Corp., Armonk, NY) was used to perform all statistical analyses. An alpha of less than 0.05 was considered indicative of statistical significance. 


\section{Results}

Table 1 shows the mean scores for each item on the cause section, as well as the results of the factor analysis. The item analysis indicated that participants mostly agreed that schizophrenia is caused by childhood trauma such as physical or sexual abuse $(4.94 \pm 1.33)$ and stress at work/school $(4.90 \pm 1.21)$, followed by a stressful familyenvironment $(4.85 \pm 1.27)$, the pressures of modern society $(4.82 \pm 1.32)$, and life trauma such as the separation or loss of a relative or close friend (4.80 \pm 1.37$)$.

The factor analysis revealed four factors for the cause section (after discountingthose with eigenvalues less than 1), which together accounted for $66.8 \%$ of the variance. Each factor was readily interpretable, with the exception of Factor 1. We ultimately labeled Factor 1 as Health/Lifestyle, as the items related to whether schizophrenia results from health status and health-related behaviors (e.g., a lack of exercise and an unhealthy diet) or lifestyle factors (e.g., lack of willpower and personality traits). Factor 2 was labeled God/Fate, as it included items related to whether schizophrenia is religious or caused by fate. Factor 3 included items relating to social factors and parenting, so it was labeled Social/Environmental. Factor 4 was labeled Biological, as it included items relating to neurotransmitters, the brain, and genetic factors (Table 1).

Table 2 shows the mean scores for each item on the treatment section, as well as the results of the factor analysis. For the individual items, participants showed the highest agreement for items indicating that schizophrenia is treated by seeing a psychiatrist $(5.23 \pm 1.22)$, taking prescribed medication or drugs $(5.12 \pm 1.12)$, and stress management $(5.01 \pm 1.18)$, followed by receiving psychotherapy (4.94 \pm 1.26$)$, seeing a counselor (4.93 \pm 1.18$)$, and cognitive behavioral therapy $(4.90 \pm 1.13)$.

The factor analysis results revealed four factors for the treatment section(after discounting those witheigenvalues of less than 1), accounting for $62.3 \%$ of the variance. All factors were readily interpretable, with the exception of Factor 2. Factor 1 was labeled Self-help/Stress Management because the items includeddealing with symptoms on one's own, stress management, and resting more. Factor 2 was ultimately labeled Physical Treatment/Health Management, and mostly included items relating to physical treatments (e.g., visiting clinics, electroconvulsive therapy, and taking oriental medicine), but also included items such as not doing anything, reading a book about schizophrenia, and seeing a social worker. Factor 3 was labeled Religious Help because it contained items on religious treatments such as being more religious, seeing a priest or religious teacher, and exorcism. Factor 4 was labeled Mental Health Service Utilization, as it included items on drug treatment, seeing a psychiatrist or counselors, hospital admission/institutionalization, receiving psychotherapy, and cognitive 
behavioral therapy (Table 2).

Table 3 shows the correlations between the scores of the cause and treatment factors. Health/Lifestyle scores were positively correlated with Self-help/Stress Management and Physical Treatment/Health Management scores, and negatively correlated with Mental Health Service Utilization scores. God/Fate scores were positively correlated with Religious Help and Physical Treatment/Health Management scores, and negatively correlated with Self-Help/Stress Management and Mental Health Service Utilization scores. Social/Environmental scores were positively correlated with Self-Help/Stress Management and Mental Health Service Utilization scores, and negatively correlated with Physical Treatment/Health Management scores. Finally, Biological scores positively correlated with Mental Health Service Utilization and Physical Treatment/Health Management scores.

\section{Discussion}

All of our hypotheses were supported. More specifically, as predicted in $\mathrm{H} 1$ and $\mathrm{H} 2$, the favored causes among Koreans were social/environmental, such as traumatic experiences (including childhood abuse and separation or loss of loved ones), stress at work/school or the family environment, and the pressures of modern society, followed bybiological, such as a chemical imbalance in the brain and brain neurotransmitter dysfunctions. Furthermore, in line with participants' beliefs about causes, the treatments believed to be most effective were those related to mental health service utilization, such asseeing a psychiatrist or counselor, taking prescribed medication or drugs, receiving psychotherapy, and cognitive behavioral therapy, followed bythose related to self-help/stress management, including stress management and obtaining the assistance of a friend or family. Moreover, theleast favored causes were those related to God/fate, such as being controlled by the devil, not following the commandments of the religion, divine punishment, and a test from God. Similarly, the least favored treatments were those related to religious help, including having a deeper faith and exorcism.

Compared to the results of a previous Korean study conducted in 2009 (Lee \& Suh, 2010) —although direct comparison between these studies is impossible due to the different questionnaires used—our study indicated that Koreans' belief in social/environmental and biological causes has strengthened, whereas their belief in the psychological and religious/supernatural causes has weakened. These results appear to suggest that the causes for and treatment of schizophrenia has changed over time showing a similar trend found in the previous Australian study (Reavley \& Jorm, 2014). Although our results have indicated that there remains a gap between current lay beliefs about the causes of schizophrenia in South Korea and the latest academic theories of schizophrenia- 
which describe biological factors as primary causes(Association, 2013; U Khan et al., 2013) —it still suggests that lay beliefs about the causes and treatments for schizophrenia have reasonably improved over time.

The factor analysis extracted four factors each for the causes and treatments of schizophrenia. All factors were comprehensible and contextually connected (save for a few items), which largely supports H3. Contents of the factors for the causes and treatments of schizophrenia found in this study mostly overlapped with those revealed in previous studies such as societal/environmental (A. Furnham \& Igboaka, 2007; Scior \& Furnham, 2016), religious/supernatural (A. Furnham \& Igboaka, 2007; Adrian Furnham \& Wong, 2007; Scior \& Furnham, 2016), and biological (Adrian Furnham \& Wong, 2007; Scior \& Furnham, 2016) factors for the causes and religious/traditional (A. Furnham \& Igboaka, 2007; Adrian Furnham \& Wong, 2007), self-help strategies (A. Furnham \& Igboaka, 2007), and psychotherapy (Adrian Furnham \& Wong, 2007) for the treatment. However, there was an interesting difference in the factor structure of the cause items between studies. In a western study, biological items tend to be classified into specific categories of biological factors, such as genetics, neurochemical changes, and miscellaneous biological factors (A. Furnham \& Igboaka, 2007), whereas all items belonged to a singular Biological factor in this study. This perhaps reflects differences in public knowledge about the causes of schizophrenia, in particular the biological causes, among populations. There is considerable benefit in identifying these differences through comparative studies, as it helps in understanding the cultural similarities and differences in MHL(Altweck et al., 2015).

The systematic correlations between the scores of the cause and treatment factors showed that laypeople have stronger beliefs about treatments of schizophrenia that correspond to their beliefs about the causes. This result is consistent with previous studies suggesting that our knowledge determines our insights about schizophrenia and actual usage of mental health services (Altweck et al., 2015; Angermeyer et al., 2013; Lee \& Suh, 2010).Since the Social/Environmental and Biological factor scores were both positively correlated with Mental Health Service Utilization scores, it is important to stress the biological and social/environmental factors as the primary causes of schizophrenia when educating others in order to improve usage of mental health services. Conversely, the Health/Lifestyle and God/Fate factor scores were both negatively correlated with the scores of Mental Health Service Utilization, which implies that preventive interventions should include correction of inaccurate knowledge about causes of schizophrenia (e.g., 'schizophrenia is caused by spirit possession').Additionally, all the cause factor scores were positively correlated with the Physical Treatment/Health Management, except for Social/Environmental. This suggests that it will be important to inform general practitioners or clinics of the 
appropriate causes and treatments of schizophrenia so that they can guide patients toward utilizing the appropriate services.

This study has some inevitable limitations. First, since the current study was investigated using across-sectional design, it is impossible to identify causal relationships between beliefs about the causes and treatments of schizophrenia. Second, the survey was conducted using an online survey, which might have led to biased sampling (e.g., more educated participants). To address these limitations, we suggest a longitudinal study with a representative sample that can clarify changes in these beliefs within a country and thereby identify the causal relations. Furthermore, further cross-cultural comparative analyses would be helpful to understand the similarities and differences in beliefs between countries.

\section{Conclusion}

This study systematically identified and analyzed lay beliefs about causes for and treatment of schizophrenia. Overall, laypeople have reasonably informed beliefs and a multidimensional viewpoint of the causes and treatments of schizophrenia. Furthermore, these beliefs are significantly correlated with each other. The results indicate that people might seek out treatment in line with what they believe about schizophrenia. Therefore, our results suggest the necessity of public education on the etiology and treatment of schizophrenia, as well providing guidelines for the screening and management of schizophrenia to primary care physicians, both of which would likely increase patients' actual seeking out of treatment for schizophrenia. This study extends knowledge on MHL as well as provides information on how to support patients in clinical settings.

Funding: This work was supported by an intramural grant from the National Center for Mental Health, Republic of Korea [grant number R2016-A]. 


\section{References}

Altweck, L., Marshall, T. C., Ferenczi, N., \& Lefringhausen, K. (2015). Mental health literacy: a crosscultural approach to knowledge and beliefs about depression, schizophrenia and generalized anxiety disorder. Frontiers in Psychology, 6, 17. doi: 10.3389/fpsyc.2015.01272

Angermeyer, M. C., \& Matschinger, H. (2003). Public beliefs about schizophrenia and depression: similarities and differences. Social psychiatry and psychiatric epidemiology, 38(9), 526-534.

Angermeyer, M. C., Millier, A., Rémuzat, C., Refaï, T., \& Toumi, M. (2013). Attitudes and beliefs of the French public about schizophrenia and major depression: results from a vignette-based population survey. BMC psychiatry, 13(1), 313.

Association, A. P. (2013). Diagnostic and statistical manual of mental disorders (DSM-5®): American Psychiatric Pub.

Chang, S. M., Cho, S.-J., Jeon, H. J., Hahm, B.-J., Lee, H. J., Park, J.-I., \& Cho, M. J. (2008). Economic Burden of Schizophrenia in South Korea. J Korean Med Sci, 23(2), 167-175.

Cho, M. J., Chang, S. M., Lee, Y. M., Bae, A., Ahn, J. H., Son, J., . . Kim, B. S. (2010). Prevalence of DSM-IV major mental disorders among Korean adults: A 2006 National Epidemiologic Survey (KECA-R). Asian J Psychiatr, 3(1), 26-30. doi: 10.1016/j.ajp.2010.01.009

Corrigan, P. W., Druss, B. G., \& Perlick, D. A. (2014). The impact of mental illness stigma on seeking and participating in mental health care. Psychological Science in the Public Interest, 15(2), 37-70.

Furnham, A., \& Anthony, E. (2010). Lay theories of bipolar disorder: the causes, manifestations and cures for perceived bipolar disorder. Int J Soc Psychiatry, 56(3), 255-269. doi: 10.1177/0020764008095173

Furnham, A., \& Igboaka, A. (2007). Young people's recognition and understanding of schizophrenia: a cross-cultural study of young people from Britain and Nigeria Int J Soc Psychiatry (Vol. 53, pp. 430-446).

Furnham, A., Ritchie, W., \& Lay, A. (2016). Beliefs about the causes and cures of depression. Int J Soc Psychiatry, 62(5), 415-424. doi: 10.1177/0020764016644279

Furnham, A., \& Wong, L. (2007). A cross-cultural comparison of British and Chinese beliefs about the causes, behaviour manifestations and treatment of schizophrenia. Psychiatry research, 151(1), 123-138.

Jensen, C. M., Martens, C. S., Nikolajsen, N. D., Gregersen, T. S., Marx, N. H., Frederiksen, M. G., \& Hansen, M. S. (2016). What do the general population know, believe and feel about individuals with autism and schizophrenia: Results from a comparative survey in Denmark. Autism, 20(4), 496-508. doi: doi:10.1177/1362361315593068

Jorm, A. F. (2000). Mental health literacy. Public knowledge and beliefs about mental disorders. $\mathrm{Br} J$ Psychiatry, 177, 396-401.

Judge, A. M., Perkins, D. O., Nieri, J., \& Penn, D. L. (2005). Pathways to care in first episode psychosis: A pilot study on help-seeking precipitants and barriers to care. Journal of Mental Health, 14(5), 465-469. 
Knapp, M., Mangalore, R., \& Simon, J. (2004). The global costs of schizophrenia. Schizophrenia bulletin, 30(2), 279.

Kohn, R., Saxena, S., Levav, I., \& Saraceno, B. (2004). The treatment gap in mental health care. Bulletin of the World health Organization, 82(11), 858-866.

Lauber, C., Nordt, C., Falcato, L., \& Rössler, W. (2003). Do people recognise mental illness? European archives of psychiatry and clinical neuroscience, 253(5), 248-251.

Lee, S., \& Suh, J. (2010). Mental Health Literacy of the Korean Public: a comparison between depression and schizophrenia. Korean J Soc Welfare Stud, 41(2), 127-158.

Magliano, L., Guarneri, M., Fiorillo, A., Marasco, C., Malangone, C., \& Maj, M. (2001). A multicenter Italian study of patients' relatives' beliefs about schizophrenia. Psychiatric Services, 52(11), 1528-1530.

Organization, W. H. (2016). Schizophrenia. Fact sheet $N$ 39. Retrieved April, 2017, from http://www.who.int/mediacentre/factsheets/fs397/en/

Reavley, N. J., \& Jorm, A. F. (2014). The Australian public's beliefs about the causes of schizophrenia: Associated factors and change over 16 years. Psychiatry research, 220(1), 609-614.

Scior, K., \& Furnham, A. (2016). Causal beliefs about intellectual disability and schizophrenia and their relationship with awareness of the condition and social distance. Psychiatry research, 243, 100-108.

Suh, S., Kim, C., \& Byoun, W. (1995). A Survey on the Knowledge and Opinions about Schizophrenia with the Family Members of the Schizophrenic Patients. J Korean Neuropsychiatr Assoc, 34(1), 204-214.

Thornicroft, G. (2008). Stigma and discrimination limit access to mental health care. Epidemiologia e psichiatria sociale, 17(01), 14-19.

U Khan, Z., Martin-Montañez, E., \& Chris Muly, E. (2013). Schizophrenia: causes and treatments. Current pharmaceutical design, 19(36), 6451-6461.

Vogt, D. (2011). Mental health-related beliefs as a barrier to service use for military personnel and veterans: a review. Psychiatric Services, 62(2), 135-142.

Yoshioka, K., Reavley, N. J., Rossetto, A., \& Nakane, Y. (2016). Associations between Beliefs about the Causes of Mental Disorders and Stigmatizing Attitudes: Results of a Mental Health Literacy and Stigma Survey of the Japanese Public. International Journal of Mental Health, 45(3), 183-192. 
Table 1. Results of a Varimax factor analysis of items that "cause" schizophrenia

\begin{tabular}{|c|c|c|c|c|}
\hline Factor/items & Loading & Eigenvalue & $\begin{array}{c}\text { Variance } \\
\text { accounted for } \\
(\%)\end{array}$ & $\begin{array}{l}\text { Mean } \\
(\mathrm{SD})\end{array}$ \\
\hline Health/lifestyle & & 6.54 & 19.23 & \\
\hline A lack of exercise & .81 & & & $3.94(1.34)$ \\
\hline An unhealthy diet & .78 & & & $3.81(1.36)$ \\
\hline Financial problems & .72 & & & $4.14(1.42)$ \\
\hline A monotonous and mundane life & .72 & & & 4.01(1.35) \\
\hline $\begin{array}{l}\text { A side-effect of some physical } \\
\text { illness }\end{array}$ & .68 & & & $4.07(1.40)$ \\
\hline Lack of will power & .67 & & & $4.06(1.42)$ \\
\hline Excessive drinking & .67 & & & $4.07(1.40)$ \\
\hline Lack of sleep & .65 & & & $4.24(1.40)$ \\
\hline Personality traits & .50 & & & $4.57(1.34)$ \\
\hline God/fate & & 6.30 & 18.53 & \\
\hline Punishment from God & .91 & & & $2.29(1.53)$ \\
\hline Being controlled by Satan & .90 & & & $2.30(1.48)$ \\
\hline Evil done in a previous life & .89 & & & $2.31(1.52)$ \\
\hline A test from God & .89 & & & $2.29(1.46)$ \\
\hline $\begin{array}{l}\text { Not following religious } \\
\text { commandments }\end{array}$ & .87 & & & $2.29(1.50)$ \\
\hline Possessed by ghosts & .86 & & & $2.43(1.58)$ \\
\hline Destiny & .86 & & & $2.48(1.56)$ \\
\hline Body temperature or energy & .62 & & & $3.04(1.53)$ \\
\hline Social/environmental & & 6.26 & 18.42 & \\
\hline $\begin{array}{l}\text { Life trauma (e.g., separation or } \\
\text { loss of a relative/close friend) }\end{array}$ & .78 & & & $4.80(1.37)$ \\
\hline $\begin{array}{l}\text { Childhood trauma (e.g., physical } \\
\text { or sexual abuse) }\end{array}$ & .76 & & & $4.94(1.33)$ \\
\hline $\begin{array}{l}\text { Being raised by parents or } \\
\text { guardians who have schizophrenia }\end{array}$ & .74 & & & $4.52(1.33)$ \\
\hline A stressful family environment & .73 & & & $4.85(1.27)$ \\
\hline Cold and uncaring parents & .72 & & & $4.41(1.35)$ \\
\hline The pressures of modern society & .68 & & & $4.82(1.32)$ \\
\hline Stress at work/school & .66 & & & $4.90(1.21)$ \\
\hline Loneliness or a lack of friends & .65 & & & $4.46(1.33)$ \\
\hline Thinking about things too much & .62 & & & $4.36(1.34)$ \\
\hline Having overprotective parents & .56 & & & $4.08(1.33)$ \\
\hline $\begin{array}{l}\text { Repressed feelings and emotions } \\
\text { in the subconscious }\end{array}$ & .51 & & & 4.61(1.28) \\
\hline Biological & & 3.60 & 10.59 & \\
\hline $\begin{array}{l}\text { A brain neurotransmitter } \\
\text { dysfunction }\end{array}$ & .81 & & & $4.62(1.32)$ \\
\hline A chemical imbalance in the brain & .80 & & & $4.55(1.35)$ \\
\hline $\begin{array}{l}\text { Abnormal size of certain areas of } \\
\text { the brain }\end{array}$ & .77 & & & $4.24(1.38)$ \\
\hline
\end{tabular}


Genetic factors

Germs or a virus that affects the brain

Unknown

.51

$4.32(1.28)$

Note: SD: standard deviation.

Table 2.Results of a Varimax factor analysis of items that 'treat' schizophrenia

\begin{tabular}{|c|c|c|c|c|}
\hline Factor/items & Loading & Eigenvalue & $\begin{array}{c}\text { Variance } \\
\text { accounted for } \\
(\%)\end{array}$ & $\begin{array}{c}\text { Mean } \\
(\mathrm{SD})\end{array}$ \\
\hline Self-help/Stress management & & 8.74 & 26.49 & \\
\hline Taking up a hobby & 0.83 & & & $4.56(1.31)$ \\
\hline Thinking positively & 0.80 & & & $4.72(1.29)$ \\
\hline Being strong emotionally & 0.76 & & & $4.40(1.33)$ \\
\hline Resting more & 0.76 & & & $4.56(1.24)$ \\
\hline Stress management & 0.75 & & & $5.01(1.18)$ \\
\hline Meditation or yoga & 0.74 & & & $4.50(1.32)$ \\
\hline Getting help from close friends & 0.74 & & & $4.60(1.21)$ \\
\hline Becoming more physically active & 0.71 & & & $4.63(1.17)$ \\
\hline Taking some time off work & 0.71 & & & $4.48(1.29)$ \\
\hline $\begin{array}{l}\text { Dealing with symptoms on one's } \\
\text { own }\end{array}$ & 0.64 & & & $4.14(1.43)$ \\
\hline Socializing more & 0.62 & & & $4.16(1.27)$ \\
\hline Family counseling & 0.62 & & & $4.59(1.25)$ \\
\hline Quitting drinking and smoking & 0.56 & & & $4.25(1.37)$ \\
\hline Change in diet & 0.54 & & & $4.12(1.31)$ \\
\hline Physical treatment/health management & & 4.34 & 13.14 & \\
\hline Going for a physical check-up & 0.71 & & & $3.87(1.41)$ \\
\hline $\begin{array}{l}\text { Visiting clinics (family medicine, } \\
\text { internal medicine, etc.) }\end{array}$ & 0.64 & & & $4.21(1.36)$ \\
\hline Taking oriental medicine & 0.62 & & & $3.33(1.52)$ \\
\hline Taking vitamins & 0.60 & & & $3.94(1.37)$ \\
\hline Electroconvulsive therapy & 0.54 & & & $3.36(1.47)$ \\
\hline Not doing anything & 0.53 & & & $3.76(1.46)$ \\
\hline Reading books about schizophrenia & 0.48 & & & $4.16(1.27)$ \\
\hline Seeing a social worker & 0.46 & & & $4.56(1.24)$ \\
\hline Religious help & & 3.89 & 11.80 & \\
\hline Being more religious & 0.82 & & & $3.10(1.62)$ \\
\hline Seeing a priest or religious teacher & 0.82 & & & $3.37(1.59)$ \\
\hline Praying & 0.81 & & & $3.48(1.60)$ \\
\hline Exorcism & 0.67 & & & $2.29(1.54)$ \\
\hline Hypnosis & 0.49 & & & $3.82(1.46)$ \\
\hline Mental health service utilization & & 3.59 & 10.89 & \\
\hline Seeing a psychiatrist & 0.85 & & & $5.23(1.22)$ \\
\hline
\end{tabular}


Taking prescribed medication or drugs

Hospital

admission/institutionalization

0.70

4.42(1.39)

Seeing a counselor

0.64

4.93(1.18)

Receiving psychotherapy

0.60

4.94(1.26)

Cognitive behavioral therapy

0.57

4.90(1.13)

Note: SD: standard deviation.

Table 3. Correlations between cause and treatment factor scores

\begin{tabular}{|c|c|c|c|c|c|c|c|c|}
\hline \multirow[t]{2}{*}{ Factor/items } & \multicolumn{2}{|c|}{ Health/lifestyle } & \multicolumn{2}{|c|}{ God/fate } & \multicolumn{2}{|c|}{$\begin{array}{c}\text { Social/ } \\
\text { environmental }\end{array}$} & \multicolumn{2}{|c|}{ Biological } \\
\hline & $r$ & $p$ & $r$ & $p$ & $r$ & $p$ & $r$ & $p$ \\
\hline Self-help/Stress management & 0.52 & $<0.001$ & -0.11 & 0.004 & 0.38 & $<0.001$ & -0.02 & 0.633 \\
\hline Physical treatment/ & & & & & & & & \\
\hline health management & 0.39 & $<0.001$ & 0.33 & $<0.001$ & -0.13 & 0.001 & 0.14 & $<0.001$ \\
\hline Religious help & 0.04 & 0.301 & 0.63 & $<0.001$ & -0.04 & 0.373 & 0.00 & 0.994 \\
\hline $\begin{array}{l}\text { Mental health service } \\
\text { utilization }\end{array}$ & -0.09 & 0.017 & -0.22 & $<0.001$ & 0.27 & $<0.001$ & 0.34 & $<0.001$ \\
\hline
\end{tabular}

